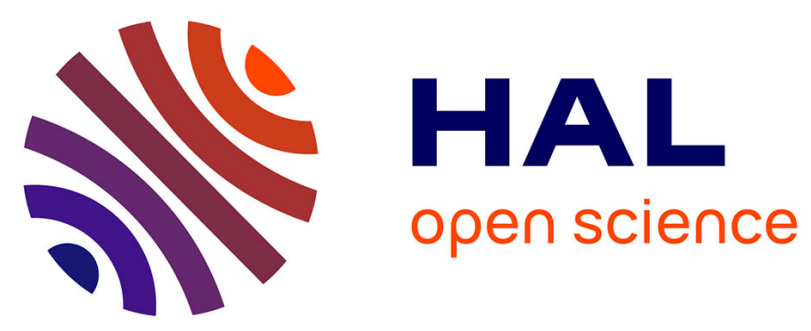

\title{
Sensitive Photoacoustic IR Spectroscopy for the Characterization of Amino/Azido Mixed-Linker Metal-Organic Frameworks
}

J. Canivet, V Lysenko, J Lehtinen, A Legrand, F Wisser, E Quadrelli, D. Farrusseng

\section{To cite this version:}

J. Canivet, V Lysenko, J Lehtinen, A Legrand, F Wisser, et al.. Sensitive Photoacoustic IR Spectroscopy for the Characterization of Amino/Azido Mixed-Linker Metal-Organic Frameworks. ChemPhysChem, 2017, 18 (20), pp.2855-2858. 10.1002/cphc.201700663 . hal-01635508

\section{HAL Id: hal-01635508 https://hal.science/hal-01635508}

Submitted on 20 Aug 2020

HAL is a multi-disciplinary open access archive for the deposit and dissemination of scientific research documents, whether they are published or not. The documents may come from teaching and research institutions in France or abroad, or from public or private research centers.
L'archive ouverte pluridisciplinaire HAL, est destinée au dépôt et à la diffusion de documents scientifiques de niveau recherche, publiés ou non, émanant des établissements d'enseignement et de recherche français ou étrangers, des laboratoires publics ou privés. 


\title{
Sensitive Photoacoustic IR-Spectroscopy for the Characterization of Amino/Azido Mixed-Linker Metal-Organic Frameworks
}

\author{
Jerome Canivet, ${ }^{*[a]}$ Vladimir Lysenko, ${ }^{*[b]}$ Jaakko Lehtinen, ${ }^{[c]}$ Alexandre Legrand, ${ }^{[a]}$ Florian M. Wisser, ${ }^{[a]}$ \\ Elsje Alessandra Quadrelli ${ }^{[\mathrm{d}]}$ and David Farrusseng ${ }^{[\mathrm{a}]}$
}

\begin{abstract}
Photoacoustic Fourier transform infrared spectroscopy makes it possible to determine the organic composition of mixedlinker metal-organic frameworks. The sound produced upon IR irradiation enables the discrimination of azido and amino linkers in three different MOF platforms with a sensitivity two orders of magnitude higher than using classic IR analysis.
\end{abstract}

Metal-organic frameworks (MOFs) are an area of innovation for chemists and materials scientists. ${ }^{[1]}$ These interesting hybrid solids have been extensively studied for their unique sorption, ${ }^{[2]}$ catalytic $^{[3]}$ and electronic properties. ${ }^{[4]}$ Their physical features arising from the large number of possible cation-linker combinations and their ability to be shaped as thin layers make them ideal candidates for the development of novel optoelectronic devices such as sensors or actuators. ${ }^{[5]}$

In this intensive exploration, new methodologies have emerged in order to characterize ever more sophisticated functional materials that embed additional organometallic, ${ }^{[6]}$ chira[ ${ }^{[7]}$ or luminescent groups, ${ }^{[4 a, 8]}$ and sometimes several of them, in a single crystalline structure. ${ }^{[9]}$ Cutting-edge spectroscopic techniques have been successfully applied to the characterization of MOF materials containing multiple functionalities gathered in a unique framework. Dynamic nuclear polarization (DNP)-enhanced NMR, ${ }^{[10]}$ rotational-echo doubleresonance (REDOR) NMR combined with molecular simulation ${ }^{[1]}$ and photothermal-induced resonance (PTIR) techniques ${ }^{[12]}$ have provided insight into the local structure, environment and spatial distribution of functional groups in mixed-linker structures. Nevertheless, these powerful characterization tools often require the use of an external chemical agent (a solvated radical for DNP. NMR) and specific sample preparation.

\footnotetext{
[a] Dr. J. Canivet, Dr. A. Legrand, Dr. F. M. Wisser, Dr. D. Farrusseng Univ. Lyon, Université Claude Bernard Lyon 1, CNRS, IRCELYON UMR 5256

2 Av. Albert Einstein, 69626 Villeurbanne, France

E-mail: jerome.canivet@ircelyon.univ-lyon1.fr

[b] Dr. V. Lysenko

Univ. Lyon, Université Claude Bernard Lyon 1, INSA Lyon, CNRS,

INL - UMR 5270

7 Av. Jean Capelle, 69621 Villeurbanne, France

E-mail : vladimir.lysenko@insa-lyon.fr

[c] Dr. Jaakko Lehtinen

Gasera Ltd.

Lemminkäisenkatu 59, 20520 Turku, Finland

[d] Dr. E. A. Quadrelli

Univ. Lyon, Université Claude Bernard Lyon 1, CPE Lyon, CNRS,

C2P2 - UMR 5265

43 Bvd du 11 Novembre 1918, 69616 Villeurbanne, France
}

Since the early 1980s, photoacoustic Fourier transform infrared spectroscopy (PA FT-IR) has been the subject of numerous technological evolutions, especially in sound collection. ${ }^{[13]}$ Beyond its application in biomedical imaging, ${ }^{[14]}$ this technique has already been used to analyze rough surfaces and gases $^{[15]}$ and has allowed the quantification of the composition of organic polymers, ${ }^{[16]}$ inorganic ceramics ${ }^{[17]}$ and hybrid zeolite membrane. ${ }^{[18]}$ PA FT-IR is based on the infrared illumination of a solid, liquid or gaseous sample. The absorption of an IR pulse induces local temperature fluctuations within the sample that result in thermal expansion, which in turn creates acoustic waves at the frequency of the IR radiation within the closed sample chamber. These acoustic waves produced are detected by a highly sensitive cantilever-type optical microphone whose vibration amplitudes are measured with a laser interferometer (Figure 1 and Scheme S1). ${ }^{[19]}$ The known advantages of PA FTIR spectroscopy are that (i) it circumvents the dependency on emitted light collection and the frequent issues with light scattering of classic FT-IR and (ii) it does not require specific sample preparation, few milligrams of the powder being simply spread on the sample holder. ${ }^{[20]}$

Here we report for the first time the correlation between the sound produced by IR-illuminated MOFs and the organic composition of their mixed-linker frameworks. Furthermore, the sensitivity determined for the detection of amino content in an azido-MOF matrix is two orders of magnitude higher using PA FTIR than using classic IR spectroscopy.

We recently reported the use of azido-to-amino turn-on luminescence of a MOF upon sulfide exposure for the sensing of $\mathrm{H}_{2} \mathrm{~S}$ as biomarker in physiological media. ${ }^{[21]}$ The amino content in the amino/azido-MOF, after exposure of the pure azido, was directly linked to the sulfide concentration of the analyzed sample solution. Similarly, we explore herein the different photoacoustic response of $\mathrm{MOF}-\mathrm{N}_{3}$ and $\mathrm{MOF}-\mathrm{NH}_{2}$, in order to ultimately determine the $\mathrm{N}_{3}$-to- $\mathrm{NH}_{2}$ molecular ratio in mixed-linker MOF powders. 


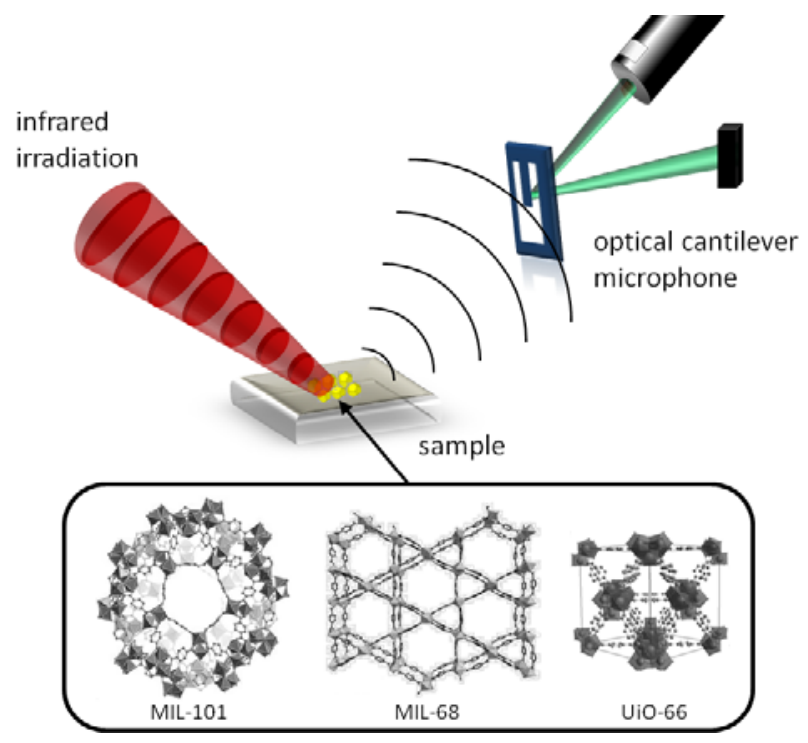

Figure 1. Schematic representation of the PA FT-IR technique applied to MOF samples: The IR laser beam (red envelope) irradiates the MOF sample. Absorption by the sample results in local thermal expansion that generates an acoustic wave detected by the optical cantilever microphone. The inset depicts the crystal structures of the three MOF samples evaluated.

We applied PA FT-IR to three different MOF types (Figure 1, Inset). In-MIL-68- $\mathrm{NH}_{2}$, patented as IHM-2, ${ }^{[22]}$ is isostructural to MIL-68 ${ }^{[23]}$ and has a one-dimensional rod-shaped structure formed of indium octahedra and 2-aminoterephthalates as bridging linkers. It is composed of hexahedral and triangular 1-D channels with diameters of 16 and $6 \AA$, respectively. Al-MIL-101$\mathrm{NH}_{2}$ is isostructural to its three-dimensional giant-pore parent $\mathrm{Cr}$ MIL-101 ${ }^{[24]}$ but made of octahedral trimeric aluminum (III) clusters and with pore diameters of 29 and $34 \AA_{.}{ }^{[25]} \mathrm{Zr}$-UiO-66- $-\mathrm{NH}_{2}$ is based on $\mathrm{Zr}_{6} \mathrm{O}_{4}(\mathrm{OH})_{4}$ clusters linked by 2-aminoterephthalates. ${ }^{[26]}$ It is also three-dimensional but has smaller accessible cavities with pore diameters of 7.5 and $11 \AA$. The azido-MOFs (MOF-N $\mathrm{N}_{3}$ ) are prepared following our previously-published method starting from the corresponding amino-functionalized structure which is allowed to react with tert-butyl nitrite and trimethylsilyl azide (see Supporting Information for detailed syntheses and characterizations). ${ }^{[27]}$ For the PA FT-IR analysis purpose, ten milligrams of MOF sample powder are spread on the holder and inserted in the measurement chamber. The typical measurement duration is 90 seconds, for a spectral range of $400-4000 \mathrm{~cm}^{-1}$.

The three platforms In-MIL-68, Zr-UiO-66 and Al-MIL-101 show similar photoacoustic behavior. In PA FT-IR spectra, two bands can be identified at $2110 \mathrm{~cm}^{-1}$, corresponding to the stretching vibrations of the azido $\mathrm{N}=\mathrm{N}=\mathrm{N}$ group, and around 1280 to $1260 \mathrm{~cm}^{-1}$, corresponding to the stretching vibrations of the C$\mathrm{N}$ bond in aromatic amines (Figure 2 and Figures S11 - S13). The signal at $1280 \mathrm{~cm}^{-1}$ is related to aromatic azides, while a signal at $1260 \mathrm{~cm}^{-1}$ corresponds to aromatic primary amines. The deconvolution of the overall signal does not, however, allow a sufficiently accurate determination of the peak area at $1260 \mathrm{~cm}^{-1}$.

As shown in the SEM micrographs provided in Figures S15S17, the size and shapes of the MOF crystallites investigated vary substantially in this study. This variation does not seem to influence the PA FT-IR signal measured in any of the samples.

For comparison, azido-functionalized samples are studied by diffuse reflectance infrared Fourier transform (DRIFT) spectroscopy (Figure 2 and Figure S9).

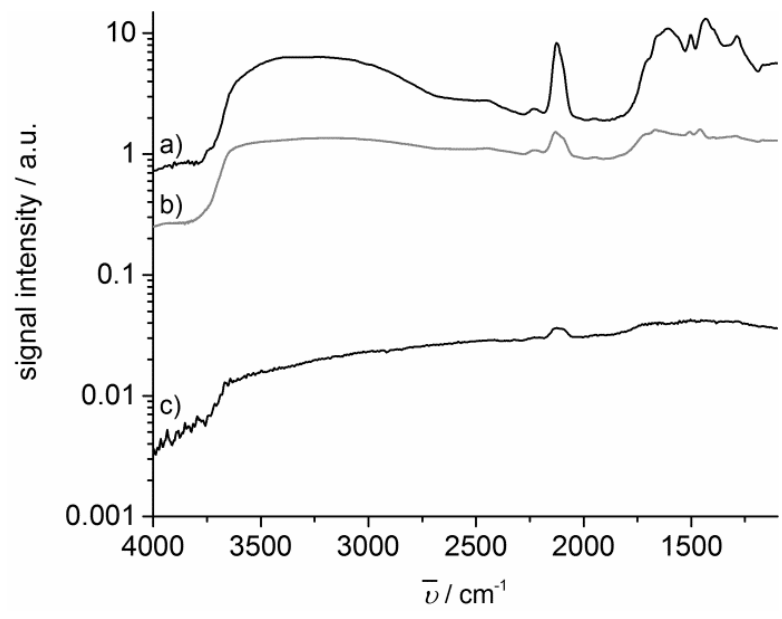

Figure 2. Collected spectra of Al-MIL-101 containing $0.3 \mathrm{~mol} \% \mathrm{NH}_{2}$ using (a) PA FT-IR, 20 scans, $8 \mathrm{~cm}^{-1}$ resolution, (b) DRIFT, 256 scans, $2 \mathrm{~cm}^{-1}$ resolution and (c) DRIFT, 20 scans, $8 \mathrm{~cm}^{-1}$ resolution.

Under the same acquisition conditions (20 scans, $8 \mathrm{~cm}^{-1}$ resolution), almost no signal can be detected using DRIFT. Similarly, under optimal acquisition conditions (256 scans, $2 \mathrm{~cm}^{-1}$ resolution), a much weaker signal is observed using DRIFT compared to the one obtained using PA FT-IR with only 20 scans and a resolution of $8 \mathrm{~cm}^{-1}$.

The variation of the PA signal intensity of peaks at 1280 and $2110 \mathrm{~cm}^{-1}$ is studied for a series of Al-MIL-101- $\mathrm{NH}_{2} / \mathrm{N}_{3}$ with molecular contents of $0.3,11.5,67.11,84.75$ and $100 \mathrm{~mol} \%$ of amino linker, respectively (Figure 3 ). The amino content in mixed azido/amino-Al-MIL-101 (in mol\% of $\mathrm{NH}_{2}$ ) is determined on the basis of ${ }^{1} \mathrm{H}$ NMR spectra of digested samples in $\mathrm{HF}-\mathrm{H}_{2} \mathrm{O} / \mathrm{dmso}^{-d^{6}}$ solution (Figure S5).

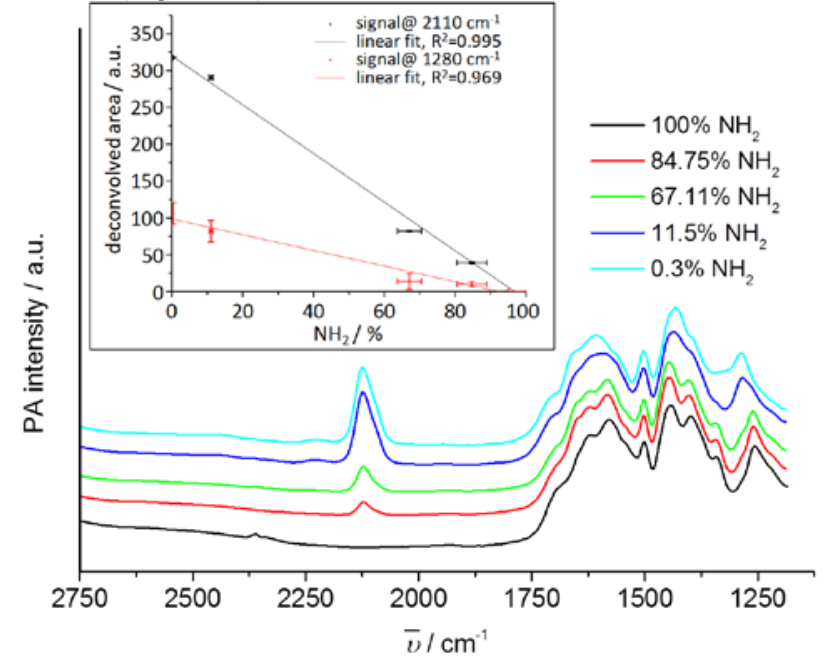


Figure 3. PA FT-IR spectra of Al-MIL-101- $\mathrm{NH}_{2} / \mathrm{N}_{3}$ with increasing molecular content of amino linker $(0.3,11.5,67.11,84.75$ and $100 \%$ from top to bottom). Samples are illuminated using an FT-IR spectrometer with a spectral range of $400-4400 \mathrm{~cm}^{-1}$ and a resolution of $8 \mathrm{~cm}^{-1}$. The PA signal is collected by an optical microphone comprising a microelectromechanical system cantilever coupled with a laser readout interferometer. Each spectrum reported corresponds to an average of 20 scans. The inset shows the linear correlation between the molecular content in amino groups and the area under the PA signal for two distinct peaks at $2110 \mathrm{~cm}^{-1}$ (top, black) and $1280 \mathrm{~cm}^{-1}$ (bottom, red).

The spectra collected clearly show a decrease in azidorelated signal intensity with decreasing azido content that occurs concomitantly with an increase in amino content.

A well-fitting linear correlation can be established between the PA signal intensity, defined as the area under the peak, and the amino content in MIL-101 (Figure 3, Inset. $\mathrm{R}^{2}=0.995$ for peak at $2110 \mathrm{~cm}^{-1}$ and $R^{2}=0.969$ for peak at $1280 \mathrm{~cm}^{-1}$, see Supporting Information for details)

Accordingly, the corresponding limit of detection $(L O D)$ for amino groups in mixed-linker Al-MIL-101 using PA FT-IR is determined to be 0.006 mol\% (see Supporting Information for mathematical definitions). Such a low $L O D$ is in high demand, for instance in sensing applications, where even minor concentration changes have to be determined precisely. ${ }^{[21]}$ For comparison, when similar data collection is carried out using DRIFT spectroscopy, a $L O D$ of only $0.304 \mathrm{~mol} \%$ of $\mathrm{NH}_{2}$-functionalized linkers is found under optimal conditions (Figure S9 and S10).

In conclusion, we report the first sound collection from IRilluminated mixed-linker MOFs to determine their organic composition (i) in the solid state, (ii) rapidly and (iii) without specific sample preparation, with a sensitivity two orders of magnitude higher than using classic IR analysis for similar measurement times. This opens up appealing new perspectives for the rapid characterization of libraries of multifunctional hybrid porous materials as well as for the use of MOFs in compact sensing devices.

\section{Experimental Section}

In a typical MOF- $\mathrm{N}_{3}$ synthesis, the freshly dried amino-functionalized MOF$\mathrm{NH}_{2}(200 \mathrm{mg})$ was treated with ${ }^{t} \mathrm{BuONO}(1.5 \mathrm{~mL})$ and $\mathrm{TMSN}_{3}(1.4 \mathrm{~mL})$ added dropwise in tetrahydrofuran (THF) $(3 \mathrm{~mL})$ in ice bath and then stirred overnight at room temperature. The resulting suspension is centrifuged and the solid washed with THF $(3 \times 5 \mathrm{~mL})$ and then with dichloromethane $(\mathrm{DCM})(3 \times 5 \mathrm{~mL})$ to give the desired product as a fine yellow powder after drying under vacuum at room temperature. The solid is finally characterized by powder $\mathrm{X}$-ray diffraction, ${ }^{1} \mathrm{H}$ liquid NMR, Diffuse Reflectance Infrared spectroscopy and $\mathrm{N}_{2}$ sorption analysis.

The FT-IR analysis was performed in diffuse reflectance mode in a DRIFT cell (Harrick) with the sample kept as powders, simply treated in situ under $\mathrm{Ar}$ flow at $100^{\circ} \mathrm{C}$. The spectrophotometer used was a Nicolet $380 \mathrm{FT}$-IR (ThermoFischer Scientific) with pyroelectric (DTGS) detector. The DRIFT spectra were recorded at a resolution of $2 \mathrm{~cm}^{-1}$ with 256 scans averaged and are reported in Kubelka Munk units.

The PA FT-IR analysis was performed in a Brüker Tensor 37 FT-IR spectrometer equipped with a GASERA PA301 detector using following parameters: measurement time 90 seconds., mirror velocity $2.2 \mathrm{kHz}$, resolution $8 \mathrm{~cm}-1$, spectral range $400-4000 \mathrm{~cm}^{-1}$, aperture $6 \mathrm{~mm}$. A typical measurement requires $10-20 \mathrm{mg}$ of solid.

\section{Acknowledgements}

The authors thank Gasera Ltd. for providing access to their facilities and are very grateful to IRCELYON scientific services. F.M.W. gratefully acknowledges financial support from the Deutschen Forschungsgemeinschaft (DFG, Postdoctoral Research Fellowship, grant number WI 4721/1-1).

Keywords: metal-organic frameworks $\bullet$ photoacoustic $\bullet$ infrared spectroscopy • azide

[1] H. Furukawa, K. E. Cordova, M. O'Keeffe, O. M. Yaghi, Science 2013 341,1230444

[2] a) E. Barea, C. Montoro, J. A. R. Navarro, Chem. Soc. Rev. 2014, 43 5419-5430; b) Y. He, W. Zhou, G. Qian, B. Chen, Chem. Soc. Rev. 2014 43, 5657-5678; c) L. J. Murray, M. Dinca, J. R. Long, Chem. Soc. Rev. 2009, 38, 1294-1314; d) B. Van de Voorde, B. Bueken, J. Denayer, D De Vos, Chem. Soc. Rev. 2014, 43, 5766-5788.

[3] a) A. Corma, H. García, F. X. Llabrés i Xamena, Chem. Rev. 2010, 110 4606-4655; b) M. Yoon, R. Srirambalaji, K. Kim, Chem. Rev. 2011, 112 1196-1231; c) A. H. Chughtai, N. Ahmad, H. A. Younus, A. Laypkov, F. Verpoort, Chem. Soc. Rev. 2015, 44, 6804-6849.

[4] a) M. D. Allendorf, C. A. Bauer, R. K. Bhakta, R. J. T. Houk, Chem. Soc Rev. 2009, 38, 1330-1352; b) T. D. Ashton, K. A. Jolliffe, F. M. Pfeffer Chem. Soc. Rev. 2015, 44, 4547-4595; c) V. Stavila, A. A. Talin, M. D. Allendorf, Chem. Soc. Rev. 2014, 43, 5994-6010.

[5] a) A. Betard, R. A. Fischer, Chem. Rev. 2012, 112, 1055-1083; b) L. E. Kreno, K. Leong, O. K. Farha, M. Allendorf, R. P. Van Duyne, J. T. Hupp, Chem. Rev. 2012, 112, 1105-1125; c) P. Falcaro, R. Ricco, C. M Doherty, K. Liang, A. J. Hill, M. J. Styles, Chem. Soc. Rev. 2014, 43 5513-5560; d) I. Stassen, M. Styles, G. Grenci, H. Van Gorp, W Vanderlinden, S. De Feyter, P. Falcaro, D. De Vos, P. Vereecken, R. Ameloot, Nat. Mater. 2016, 15, 304-+; e) V. Stavila, C. Schneider, C Mowry, T. R. Zeitler, J. A. Greathouse, A. L. Robinson, J. M. Denning, J. Volponi, K. Leong, W. Quan, M. Tu, R. A. Fischer, M. D. Allendorf, Adv. Funct. Mater. 2016, 26, 1699-1707.

[6] a) J. D. Evans, C. J. Sumby, C. J. Doonan, Chem. Soc. Rev. 2014, 43, 5933-5951; b) W. M. Bloch, A. Burgun, C. J. Coghlan, R. Lee, M. L. Coote, C. J. Doonan, C. J. Sumby, Nature Chem. 2014, 6, 906-912; c) J. Canivet, S. Aguado, Y. Schuurman, D. Farrusseng, J. Am. Chem. Soc. 2013, 135, 4195-4198; d) H. H. Fei, S. M. Cohen, J. Am. Chem. Soc. 2015, 137 2191-2194; e) C. Wang, Z. G. Xie, K. E. deKrafft, W. L. Lin, J. Am. Chem. Soc. 2011, 133, 13445-13454.

[7] a) L. Ma, C. Abney, W. Lin, Chem. Soc. Rev. 2009, 38, 1248-1256; b) M Banerjee, S. Das, M. Yoon, H. J. Choi, M. H. Hyun, S. M. Park, G. Seo, K. Kim, J. Am. Chem. Soc. 2009, 131, 7524-7525; c) D. J. Lun, G. I. N. Waterhouse, S. G. Telfer, J. Am. Chem. Soc. 2011, 133, 5806-5809; d) C.-D. Wu, A. Hu, L. Zhang, W. Lin, J. Am. Chem. Soc. 2005, 127, 89408941; e) J. Bonnefoy, A. Legrand, E. A. Quadrelli, J. Canivet, D. Farrusseng, J. Am. Chem. Soc. 2015, 137, 9409-9416.

[8] a) Y. Cui, Y. Yue, G. Qian, B. Chen, Chem. Rev. 2011, 112, 1126-1162; b) Y. Qian, L. Zhang, S. Ding, X. Deng, C. He, X. E. Zheng, H.-L. Zhu, J. Zhao, Chem. Sci. 2012, 3, 2920-2923.

[9] a) M. M. Wanderley, C. Wang, C.-D. Wu, W. Lin, J. Am. Chem. Soc. 2012 134, 9050-9053; b) Z. J. Zhang, H. T. H. Nguyen, S. A. Miller, S. M. Cohen, Angew. Chem. Int. Ed. 2015, 54, 6152-6157; c) P. V. Dau, S. M. Cohen, Inorg. Chem. 2015, 54, 3134-3138.

[10] a) A. J. Rossini, A. Zagdoun, M. Lelli, J. Canivet, S. Aguado, O. Ouari, P. Tordo, M. Rosay, W. E. Maas, C. Copéret, D. Farrusseng, L. Emsley, A. Lesage, Angew. Chem. Int. Ed. 2012, 51, 123-127; b) T. K. Todorova, X Rozanska, C. Gervais, A. Legrand, L. N. Ho, P. Berruyer, A. Lesage, L. Emsley, D. Farrusseng, J. Canivet, C. Mellot-Draznieks, Chem. Eur. J. 2016, 22, 16531-16538. 
[11] X. Q. Kong, H. X. Deng, F. Y. Yan, J. Kim, J. A. Swisher, B. Smit, O. M. Yaghi, J. A. Reimer, Science 2013, 341, 882-885.

[12] A. M. Katzenmeyer, J. Canivet, G. Holland, D. Farrusseng, A. Centrone, Angew. Chem. Int. Ed. 2014, 53, 2852-2856.

[13] a) V. Koskinen, J. Fonsen, K. Roth, J. Kauppinen, Appl. Phys. B-Lasers O. 2007, 86, 451-454; b) T. Kuusela, J. Kauppinen, Appl. Spectrosc. Rev. 2007, 42, 443-474; c) P. Sievila, V. P. Rytkonen, O. Hahtela, N Chekurov, J. Kauppinen, I. Tittonen, J. Micromech. Microeng. 2007, 17 852-859; d) V. Koskinen, J. Fonsen, K. Roth, J. Kauppinen, Vib. Spectrosc. 2008, 48, 16-21.

[14] a) M. H. Xu, L. H. V. Wang, Rev. Sci. Instrum. 2006, 77; b) L. V. Wang Nat. Photon. 2009, 3, 503-509; c) Y. J. Liu, L. M. Nie, X. Y. Chen, Trends Biotechnol. 2016, 34, 420-433; d) L. H. V. Wang, J. J. Yao, Nat. Methods 2016, 13, 627-638.

[15] K. H. Michaelian, "Photoacoustic IR Spectroscopy: Instrumentation, Applications and Data Analysis, 2nd, Revised and Enlarged Edition", Wiley-VCH, 2010.

[16] R. S. Pandurangi, M. S. Seehra, Appl. Spectrosc. 1992, 46, 1719-1723.

[17] J. F. McClelland, R. W. Jones, S. Q. Luo, Rev. Sci. Instrum. 2003, 74 , 285-290.

[18] W. Oh, S. Nair, J. Phys. Chem. B 2004, 108, 8766-8769.

[19] J. Kauppinen, K. Wilcken, I. Kauppinen, V. Koskinen, Microchem. J. 2004 76, 151-159.

[20] D. W. Vidrine, Appl. Spectrosc. 1980, 34, 314-319.

[21] A. Legrand, A. Pastushenko, V. Lysenko, A. Geloen, E. A. Quadrelli, J. Canivet, D. Farrusseng, Chemnanomat 2016, 2, 866-872.

[22] M. Savonnet, D. Farrusseng, C. Pinel, D. Bazer-Bachi, N. Bats, V. Lecocq, "Novel organic/inorganic hybrid material IHM-2, and methods for manufacturing same", Patent PCT Appl. WO2011048284 2011.

[23] a) K. Barthelet, J. Marrot, G. Ferey, D. Riou, Chem. Commun. 2004, 520521; b) BASF, Patent 2008; c) A. Fateeva, P. Horcajada, T. Devic, C Serre, J. Marrot, J. M. Greneche, M. Morcrette, J. M. Tarascon, G. Maurin G. Ferey, Eur. J. Inorg. Chem. 2010, 3789-3794; d) C. Volkringer, M. Meddouri, T. Loiseau, N. Guillou, J. Marrot, G. Ferey, M. Haouas, F. Taulelle, N. Audebrand, M. Latroche, Inorg. Chem. 2008, 47, 1189211901; e) M. Savonnet, D. Bazer-Bachi, N. Bats, J. Perez-Pellitero, E. Jeanneau, V. Lecocq, C. Pinel, D. Farrusseng, J. Am. Chem. Soc. 2010 $132,4518-4519$

[24] a) G. Ferey, C. Mellot-Draznieks, C. Serre, F. Millange, J. Dutour, S. Surble, I. Margiolaki, Science 2005, 309, 2040-2042; b) M. Latroche, S Surble, C. Serre, C. Mellot-Draznieks, P. L. Llewellyn, J.-H. Lee, J.-S Chang, S. H. Jhung, G. Ferey, Angew. Chem. Int. Ed. 2006, 45, 82278231.

[25] a) M. Hartmann, M. Fischer, Microporous Mesoporous Mater. 2012, 164 , 38-43; b) P. Serra-Crespo, E. V. Ramos-Fernandez, J. Gascon, F. Kapteijn, Chem. Mater. 2011, 23, 2565-2572.

[26] M. Kandiah, M. H. Nilsen, S. Usseglio, S. Jakobsen, U. Olsbye, M. Tilset, C. Larabi, E. A. Quadrelli, F. Bonino, K. P. Lillerud, Chem. Mater. 2010 22, 6632-6640.

[27] M. Savonnet, D. Bazer-Bachi, N. Bats, J. Perez-Pellitero, E. Jeanneau, V. Lecocq, C. Pinel, D. Farrusseng, J. Am. Chem. Soc. 2010, 132, 45184519 
